after injection of fluorine, oxalate, citrate, phosphorus and molybdenum. None of these substances, except fluorine, caused any change in the organic enamel.

While these results need considerable expansion, certain interesting points arise from them. While fluorine acts on both enamel and dentin, the other elements that imitate its action act only on the dentin. It has been already shown that the action of fluorine on the enamel is independent of the calcium-phosphorus ratio of the diet but that on dentin depends

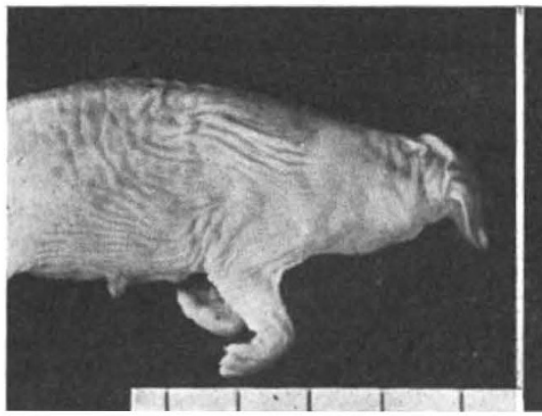

FIG. 1.

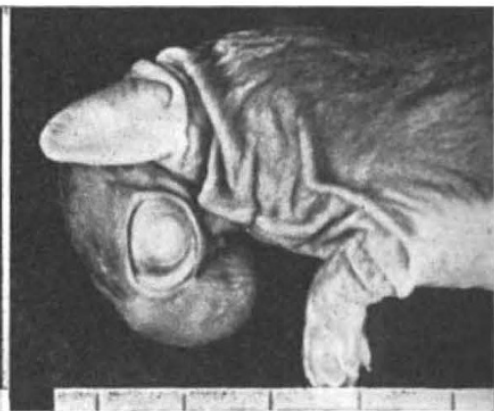

FIG. 2. on the calcium-phosphorus ratio, and it would appear possible that the first action is a direct one on the enamel organ, the second indirect, by altering the concentration of blood constituents. If this is true, then it would also be safe to conclude that the other substances here examined also act not only by altering the composition of the blood but have no direct action on the tooth. In any event it would be unlikely that such a diverse number of substances would act directly on the tooth, but they are all such as might affect calcium or phosphorus metabolism. It is interesting to note that with low ratio diets, tetany is not a requisite for the calcifying action in the predentin. Citrate in particular caused violent tetany, but had no effect on the tooth.

To summarize, it is possible experimentally to affect organic enamel and predentin formation separately or together. On normal ratio diets, fluorine affects both; on high ratio diets, fluorine affects only organic enamel formation; while on low ratio diets, phosphorus, and possibly other substances, affeet only predentin formation.

Department of Physiology,

J. T. IRving.

Medical School,

University of Cape Town. June 6.

${ }^{1}$ Weinmann, J. P., J. Dent. Res., 21, 497 (1942).

'Wessinger, G. D., and Weinmann, J. P., Amer. J. Physiol., 189, 233 (1943).

Irving, J. T., Nature, 151, 363 (1943).

- Irving, J. T., J. Dent. Res., 22, 447 (1943).

- Irving, J. T., results to be published.

\title{
Artificial Production of Monstrosities in the Rabbit
}

Four doe rabbits of unknown breeding were inseminated with the spermatozoa of one male suspended in a solution of 0.1 per cent colchicine in 0.9 per cent sodium chloride. Doe No. 8 gave birth to six normal young and one monster (Fig. 1). No. 13 gave birth to ten normal young; but on the following day was discovered devouring an eleventh, the normality or abnormality of which could not be determined. No. 14 gave birth to eight normal and one monster (Fig. 2). No. 16 gave birth to five normal and one with unclosed anterior fontanelle (Bregma) and with very small philtrum. This lived only five days. The experimental animals gave, therefore, twenty-nine normal young, two definite monsters, one defective young and one uncertain. In previous inseminations the same does had given fifty-nine young without abnormality.

Since February, forty does of similar origin but also unknown heredity had produced 425 young from spermatozoa suspended in 0.9 per cent sodium chloride and no abnormalities had been observed.

In extensive rabbit breeding in Cambridge, similar monstrosities have not been observed. It seems therefore most probable that these monsters were produced by the colchicine, although it will be neces. sary to repeat the experiment on a larger scale and with inbred strains of known heredity in order to make quite certain that the results are not due to chance.

If attributable to the colchicine, it is likely that the effect is due to polyploidy or some disturbance of the nuclear mechanism or organizers in the tissues affected.

The effects of colchicine may be due to the substance being carried into the ovum by the sperm. atozoan, or being present in the oviduct and uterus and affecting the fertilized ovum at a later stage of development. Pincus and Waddington ${ }^{1}$ treated fertilized ova in vitro with colchicine and other chemicals, and concluded that colchicine appears to be especially effective not only in preventing spindle formation and cytoplasmic cleavage, but also in inhibiting the normal movements of the pronuclei; tetraploid ova produced, failed to cleave over a culture period of one day, and the few that did cleave did so at a subnormal rate. Polyploidy has been produced artificially in insects and amphibian larvæ, but not so far as I am aware in mammalian embryos. Further systematic experimentation is planned in the hope that it may throw some light on the causes of embryonic monstrosities.

School of Agriculture,

University, Cambridge. June 8.

${ }^{2}$ Pincus, G,, and Waddington, C. H., J. Heredity, 30, 315 (1939).

\section{Wöhler's Work on Urea}

IN his interesting article on Wöhler's work on urea $^{1}$, Dr. Douglas McKie states that words spoken by W. v. Hofmann in 1882 in his obituary of Wöhler have given rise to a legend that Wöhler synthetized urea, thereby sounding the death-knell of the hypothesis of vitalism. I do not think any such legend exists.

It is well known that Wöhler arrived at urea through transformation of ammonium cyanate. There is no other interpretation of this fact, therefore also no legend. Dr. MeKie bases his attack on 